\title{
O NÍVEL DE SERVIÇO DE UM CONSOLIDADOR DE CARGAS MARÍTIMAS SOB A ÓTICA DOS USUÁRIOS
}

\section{THE LEVEL OF SERVICE OF A SEA-FREIGHT CONSOLIDATOR UNDER CUSTOMER'S PERCEPTION}

\author{
Guilherme Bergmann Borges Vieira \\ Professor e Pesquisador \\ Universidade de Caxias do Sul \\ Departamento de Administração \\ Av. Francisco Getúlio Vargas, 1130 - B. Petrópolis - CEP 95070-560 - Caxias do Sul - RS \\ Telefone: (54) 218-2174Ｅ-mail: gbvieira@cpovo.net
}

\author{
Sergio Luis Alves Rodrigues \\ Profissional de Comércio Exterior/ Mestrando em Administração \\ Universidade do Vale do Rio dos Sinos \\ Av. Unisinos, 950 - Bairro Cristo Rei - CEP 93.022-000 - São Leopoldo - RS \\ Telefone: (51) 32262992 E-mail: sarodrigues@craft.com.br
}

\begin{abstract}
RESUMO
A concorrência acirrada tem forçado as empresas a adequarem-se às mutantes demandas dos consumidores, visando criar posições vantajosas no mercado. Os serviços, intangíveis e de difícil mensuração, possuem diversos atributos competitivos que não são uniformemente importantes para os usuários. Portanto, identificar os atributos ma is importantes e avaliar o desempenho de uma organização em relação aos mesmos é fundamental para a proposta consistente de valor ao mercado. Este estudo procurou identificar e avaliar os atributos competitivos de um consolidador de cargas marítimas atuante no mercado gaúcho. Os atributos que formaram o questionário de avaliação da satisfação, submetido ao universo de clientes da empresa, foram identificados em pesquisas anteriores feitas pela organização, complementados por revisão bibliográfica e validados por pré-teste. Os níveis de satisfação em relação a cada atributo foram atribuídos pelos próprios respondentes e os graus importância foram obtidos de forma indireta, por meio de regressão múltipla. Os resultados destacaram um elevado desempenho da empresa nos aspectos referentes a preparo técnico de sua equipe e atendimento aos clientes. O estudo gerou subsídios consistentes para a melhoria contínua dos serviços e identificou fatores importantes na escolha de empresas desse tipo.
\end{abstract}

Palavras-chave: Logística. Consolidação marítima. Nível de serviço. 


\begin{abstract}
The strong competition has forced today's organizations to continuously adjust their product mix to the changing consumer's demands in order to create advantageous position in the marketplace. Services, intangible and difficult to measure, have several competitive attributes which are not equally important at customer's perception. Based on that, identifying the most important attributes and measuring organization's performance against the same is a key point for a consistent value proposal to the market. This paper attempted to investigate the competitive attributes of a sea-freight consolidator provider located at the State of Rio Grande do Sul. The results emphasized company's outstanding performance regarding staff's technical skills and customer services. The high importance of these attributes at customer's perception enables the company to offer a differenced value package to its targeted market. This paper also generated consistent information for the continuous improvement of company's services as well as identified important factors of customer's selections criteria for this industry companies.
\end{abstract}

Key-words: Logistics. Sea-freight consolidation. Level of service.

\title{
1. INTRODUÇÃO
}

O setor de consolidação de cargas marítimas tem experimentado uma competição cada vez maior, uma vez que a baixa intensidade de capital favorece o acesso de novos entrantes. Corre-se o risco de que, à primeira vista, os serviços prestados pareçam semelhantes para os usuários. A alta velocidade da informação faz com que diferenciais competitivos sejam copiados rapidamente e a facilidade de acesso a novas fontes de prestação de serviços tem levado as empresas à busca incessante pela diferenciação perante seu público-alvo. Com a empresa estudada não poderia ser diferente. Acossada pelo panorama atual de grande concorrência e de quedas abruptas nas margens de lucro, a organização vislumbra a oferta de valor ao cliente como saída estratégica para diferenciação de sua marca no longo prazo.

Para Christopher (1999), o valor ao cliente é criado quando as percepções dos benefícios recebidos em uma transação superam os custos totais de propriedade ou uso. $\mathrm{O}$ valor e a formação de uma estratégia de diferenciação através de serviços que agreguem esse valor estão intimamente ligados à satisfação dos clientes, satisfação essa que depende de sua percepção ante os níveis de serviços prestados por uma organização. Segundo Unruh (1998), compreender o que os clientes valorizam constitui a base fundamental para o êxito empresarial na focalização do cliente.

Com o crescimento da conteinerização, os embarques consolidados também têm aumentado nos últimos anos, tanto no Brasil como no Rio Grande do Sul. Entretanto, apesar 
da crescente importância da consolidação marítima, não foram encontrados na bibliografia estudos sobre a satisfação dos usuários em relação a esses prestadores de serviços, privando profissionais e acadêmicos do setor de um conhecimento mais profundo sobre os níveis de serviços prestados e sobre os critérios de escolha de um consolidador.

Diante desse panorama, o presente estudo justifica-se por oportunizar uma abordagem sobre o nível de serviços de um consolidador de cargas marítimas e os atributos considerados pelos usuários na escolha de uma empresa desse tipo. Sendo assim, o objetivo principal foi avaliar o nível de serviço de um consolidador atuante no mercado do Rio Grande do Sul sob a ótica dos usuários de seus serviços. Para tanto, o estudo se propôs a: i) identificar os atributos considerados pelos usuários na escolha do prestador de serviços de consolidação marítima; ii) verificar o nível de satisfação dos usuários em relação a cada atributo considerado, bem como seus respectivos graus de importância; iii) a partir da análise do nível de satisfação e do grau de importância verificado para cada atributo, sugerir estratégias a serem adotadas pela empresa, visando ganho de competitividade.

Embora se tenha dado ênfase apenas aos usuários de serviços de transporte marítimo consolidado do Estado do Rio Grande do Sul, cadastrados como clientes da organização estudada, este trabalho tem relevância, devido à grande participação da empresa no mercado em questão.

\section{DESENVOLVIMENTO DA CONTEINERIZAÇÃO, SURGIMENTO E CARACTERIZAÇÃO DOS NVOCCs (Non Vessel Operating Common Carriers)}

Inicialmente, o embarque de mercadorias no transporte marítimo era realizado de forma individual, por unidade, o que conferia à operação um alto grau de morosidade, levando navios a permanecerem muito tempo nos portos, incorrendo em altos custos operacionais e não permitindo um índice satisfatório de rotatividade da embarcação. Diante dessa realidade, desenvolve-se a unitização de cargas no transporte marítimo, conceito que contempla desde os rudimentares amarrados e engradados até os contêineres da atualidade.

Segundo Novaes (1976), os primeiros registros de um equipamento similar ao contêiner datam de 1911, quando a National Geographic Magazine teria fotografado uma unidade sendo içada a bordo de um navio nos Estados Unidos. Conforme Faria (2001), o contêiner foi usado pelas Forças Armadas Americanas na Segunda Guerra Mundial, no transporte de armas, munições e mantimentos para as tropas aliadas no campo de combate. Com o fim da guerra, o contêiner foi adaptado para fins comerciais, dando início à corrida da 
conteinerização. Com vistas à utilização do contêiner de forma mundial, fez-se necessária a criação de um padrão único, aceito e utilizado mundialmente, o que foi feito pela ISO (International Organization for Standarization).

Nas últimas décadas, o contêiner tem apresentado níveis de utilização crescentes, principalmente às custas de reduções da carga geral solta (AGÓS, 1993). Segundo Keedi (2002), a movimentação de contêineres em 2001 atingiu a marca de 200 milhões de unidades, sendo que a expectativa para 2010 é de que mais de 400 milhões de contêineres sejam movimentados mundialmente. De acordo com dados do Trainmar (2003), a utilização de contêiner apresentou um crescimento de 9,2\% no período 2001/2002, o que representa um crescimento médio de $170 \%$ acima do crescimento médio do PIB mundial.

Sem dúvida, esse crescimento tem uma explicação lógica, já que a conteinerização traz várias vantagens aos diferentes participantes da cadeia logística internacional. A utilização do contêiner oportuniza redução de risco à carga; diminuição dos custos de transporte, devido às economias de escala; redução dos custos portuários; maior velocidade nas operações de carga e descarga, entre outras vantagens.

Contudo, sua popularização trouxe à tona um problema a ser solucionado: embarques cujos volumes não atingissem o mínimo necessário para a utilização razoável de um cofre. Visando a resolver essa questão, os armadores passaram a oferecer os serviços de ship's convenience, que podem ser definidos como embarques de lotes consolidados de vários exportadores a vários importadores, com o enchimento do contêiner no porto de origem e a desova no porto de destino por conta e risco do armador. Entretanto, apesar de desempenharem um importante papel na inclusão de pequenos lotes à era da conteinerização, os serviços de ship's convenience não atendiam de forma adequada as necessidades dos usuários e não permitiam o eficiente gerenciamento da cadeia de suprimentos.

Segundo Bowersox e Closs (2001), o gerenciamento da cadeia de suprimentos deve contemplar seis objetivos operacionais: i) resposta rápida, que é a habilidade de satisfazer as exigências de serviço ao cliente em tempo hábil; ii) variância mínima, ou seja, o ato de evitar que qualquer evento inesperado perturbe o desempenho do sistema; iii) estoque mínimo, visando a uma maior rotatividade do mesmo; iv) consolidação da movimentação, ou seja, reduzir os custos de transporte pelo agrupamento de vários lotes em um único embarque; v) qualidade, ou o comprometimento com a tolerância zero aos defeitos, evitando perdas e retrabalhos; vi) apoio ao ciclo de vida, ou seja, o desenvolvimento logístico da cadeia, envolvendo não somente o produto em si, mas também todo o processo de pós-venda.

Sob essas premissas, o serviço de ship’s convenience apresentava sérias limitações, 
uma vez que o embarque estava sujeito à conveniência do armador, incorrendo em atrasos e em uma inaceitável irregularidade. Nesse ambiente propício, surgiram os NVOCCs (Non Vessel Operating Common Carrier) que, segundo Brodie (1985), podem ser definidos como empresas que não são proprietárias ou operadoras de navios, mas que contratam junto a uma companhia marítima espaços para o transporte de mercadorias de terceiros. Buscando diferenciar sua oferta dos serviços de ship's convenience, os NVOCCs prestam serviços de transporte de pequenos lotes com saídas mais regulares e com uma cobertura geográfica mais abrangente, oferecendo ao cliente o valor de ter suas cargas transportadas a destinos mais distantes e com uma garantia de entrega compatível a sua conveniência, não à do navio.

De acordo com Bowersox e Closs (2001), o transporte, assim como a manufatura, é suscetível a economias de escala. Sob essa perspectiva, materializar uma oferta ampliada de pontos de entrega no mundo, mantendo custos viáveis de transporte, é um desafio significativo para os NVOCCs. Diante disso, essas empresas buscam utilizar portos concentradores de carga (hub ports) e formar alianças estratégicas, visando cooperar em seus embarques, gerando volumes e, conseqüentemente, novos tráfegos a serem operados e ofertados aos seus clientes.

\section{A EMPRESA ESTUDADA E O MERCADO DE CONSOLIDAÇÃO MARÍTIMA}

\subsection{Caracterização da empresa estudada}

Fundada em 1997, por emp resários paulistanos, a empresa possui matriz em São Paulo e filiais em Limeira, Santos, Rio de Janeiro, Curitiba, Itajaí, Porto Alegre e Buenos Aires. A organização conta com consolidações a partir de Santos, Itajaí, Rio Grande, Paranaguá e Rio de Janeiro, sendo Santos e Rio Grande os principais portos de origem.

Contando com 115 profissionais no Brasil e agentes nos principais portos do mundo e cobrindo aproximadamente 500 destinos através dos principais hubs ports, a organização apresenta um faturamento de aproximadamente $\mathrm{R} \$ 30.000 .000,00$ por ano.

No Brasil, segundo estatísticas do Centro de Navegação do Porto de Santos, a empresa detém a liderança de mercado, com 54,36\% de um total de 8.723 TEUs (Twenty Feet equivalent Units - unidades de contêineres de vinte pés) estimados em 2003, contra 27,24\% de seu principal concorrente. Sua posição no mercado do Rio Grande do Sul também é bastante favorável. Segundo dados do Centro de Navegação do Porto de Rio Grande, sobre as cargas embarcadas nesse porto no ano de 2003, a empresa apresentou posição de liderança em 
relação a seus seis concorrentes. Considerando o total de contêineres embarcados com cargas consolidadas (884 TEUs), a empresa teve 48,53\% de participação, contra 38,91\% de seu principal concorrente; $9,28 \%$ do terceiro colocado e 3,28\% dos demais competidores. Além disso, o índice de satisfação de seus clientes é elevado (88\%), conforme pesquisa realizada pela gerência de sua filial gaúcha no primeiro trimestre de 2003.

\subsection{O mercado de consolidação manítima e a intensidade da concorrência}

A demanda por transporte de carga marítima consolidada no Brasil tem apresentado elevado crescimento nos últimos anos, conforme se pode observar na figura 1.

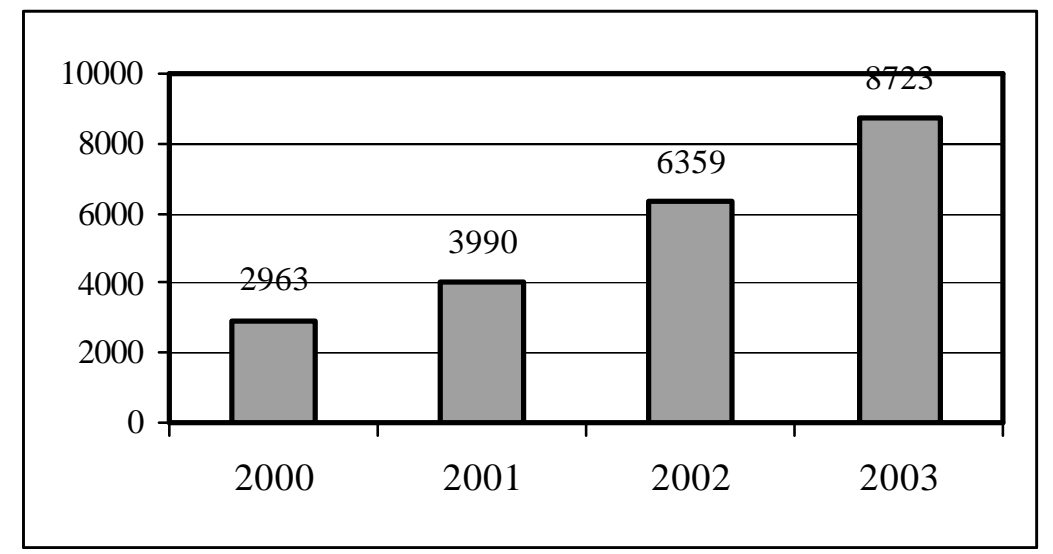

Figura 1: Demanda por transporte marítimo consolidado no Brasil

(em TEUs - Twenty Feet equivalent Units, unidades de contêineres de vinte pés)

Fonte: Centronave - Centro de Navegação do Porto de Santos

No mercado do Rio Grande do Sul, a situação não é diferente. Segundo o Centronave, em 2003 foram movimentados 1.209 TEUs por NVOCCs, contra 916 em 2002 e 551 em 2001, representando um crescimento de 66,24\% de 2001 para 2002; 31,99\% de 2002 para 2003 e 119,42\% no período. Esse crescimento recente da consolidação nos mercados brasileiro e gaúcho tem atraído os olhos de empreendedores, tornando o mercado cada vez mais concorrido.

Segundo Porter (1986), cinco são as forças que dirigem a intensidade da concorrência em uma indústria, bem como sua rentabilidade: entrantes potenciais, ameaça de substituição, poder de negociação dos compradores, poder de negociação dos fornecedores e rivalidade entre os atuais concorrentes.

Com a baixa necessidade de capital inicial, a potencialidade de novos entrantes no 
setor de consolidação marítima é alta. Empresas internacionais, cujo negócio principal é o agenciamento de cargas, podem iniciar suas atividades como NVOCCs sempre que lhes for conveniente, ainda que não apresentem um volume de carga suficiente para oferecer serviços regulares.

Devido ao baixo custo de mudança que une os NVOCCs a seus clientes e à crescente oferta de serviços de consolidação marítima, o poder de negociação dos compradores também é alto, colocando as empresas em estado de alerta pela manutenção de sua participação no mercado.

Por suas características singulares, o transporte marítimo consolidado conta com a concorrência dos modais aéreo e rodoviário. Nos meses de verão, por exemplo, devido à safra de frutas do Chile, a oferta de caminhões a Santiago é ampliada, fazendo com que a demanda pelo modal marítimo para os portos de San Antonio e Valparaíso diminua. Nas exportações para_países como a Argentina e o Uruguai, devido à pouca oferta de conexões marítimas e também pela proximidade geográfica, as empresas tendem a optar pelo transporte rodoviário, amplamente ofertado no Brasil e com custos bastante atrativos.

Como os NVOCCs contratam dos armadores fretes de contêineres completos para revendê-los em lotes menores aos seus clientes, eles são muito sensíveis ao poder dos fornecedores, pois trata-se de um mercado altamente concentrado em poucas empresas. Segundo a OECD (2002), os 20 principais operadores de transporte conteinerizado representam $72 \%$ da capacidade global de transporte. Esse fato, aliado às diversas formas de cooperação entre os participantes desse negócio, confere um alto poder aos armadores sobre os níveis de frete praticados.

Observa-se que, no mercado de cargas marítimas consolidadas, existem vários participantes regionais, porém somente três empresas, entre as quais a estudada, apresentam cobertura nacional. Essas empresas dividem entre si grande parte do mercado brasileiro, cabendo aos demais concorrentes uma participação secundária em regiões e setores específicos.

\subsection{Abordagens estratégicas dos competidores no mercado brasileiro}

Segundo Porter (1986), existem três abordagens estratégicas potencialmente exitosas para superar a concorrência: liderança em custos; diferenciação do produto ou serviço e enfoque. No setor de consolidação de cargas marítimas, os principais concorrentes adotam abordagens estratégicas distintas de atuação no mercado brasileiro. Entretanto, as abordagens 
de cada concorrente são as mesmas, tanto no mercado nacional, quanto nos mercados regionais.

A empresa estudada baseia toda sua operação na busca pela diferenciação de seus serviços, focando suas atividades no atendimento ao cliente e na abrangência e regularidade de seus embarques. Tal estratégia garante à organização uma posição confortável perante os concorrentes, devido à lealdade de seus clientes. Essa política, contudo, mostra-se ineficaz em mercados muito sensíveis ao preço.

A principal concorrente da empresa adota uma política de liderança em custos, mantendo preços mais baixos do que a média do mercado. Embora essa política apresente vantagens, é a mais simples de ser copiada, o que pode colocar em risco a sobrevivência da organização a longo prazo.

A terceira força do mercado nacional de NVOCC oferece saídas de todo o território nacional com destino ao mercado europeu, garantindo bons resultados nessa área geográfica. Trata-se da estratégia de enfoque, que garante a possibilidade de uma diferenciação de seus serviços por meio do relacionamento mais estreito com seu público-alvo (PORTER, 1986). Essa proximidade poderá significar, também, a oportunidade de obter a liderança em custos totais de seu mercado específico, devido a seu amplo desenvolvimento na curva do conhecimento do setor (PORTER, 1986). No mercado de NVOCC, contudo, a adoção dessa estratégia poderá limitar perigosamente as economias de escala da empresa, afetando a cobertura e a regularidade dos serviços.

\section{DIFERENCIAÇÃO POR SERVIÇOS}

Em um ambiente de elevada concorrência como o da consolidação de cargas marítimas, a busca pela diferenciação faz-se necessária para não somente melhorar o resultado de uma empresa, mas também garantir sua sobrevivência no longo prazo, quando da maturação de sua indústria.

Segundo Ohmae, apud Rust et al. (2001), a estratégia adequada ao ambiente atual é aquela em que a essência da empresa é tornar-se fornecedora de valor para o cliente, encontrando maneiras novas e mais eficazes para atender as necessidades destes. Valor, de acordo com Christopher (1999), é a razão entre as percepções que o cliente tem dos benefícios de um determinado produto ou serviço e o custo total de propriedade. Assim, a criação de valor, em vez de apenas produtos e serviços, deve ser a meta primordial de toda e qualquer empresa que almeje sobreviver no cenário atual de mudanças. 
Atender as necessidades dos clientes, sem dúvida, tem se tornado a grande premissa deste milênio. E, para esse fim, é essencial compreender os anseios dos clientes e quais são os atributos considerados no ato da decisão de compra (UNRUH, 1998).

Entretanto, dada a intangibilidade dos serviços, a identificação dos critérios considerados por um usuário no processo de escolha de um fornecedor é bastante complexa. Por essa razão, os elementos que constituem o nível de serviço e seu impacto no comportamento de compra dos usuários têm sido o foco de diversos estudos nos últimos anos. Contudo, tais estudos não apresentam uma resposta definitiva a esse questionamento, uma vez que os próprios clientes não conseguem identificar facilmente o que motiva seu comportamento de compra (BALLOU, 2001). Porém, as pesquisas são importantes ferramentas no esclarecimento dessa relação e seu uso apropriado é, sem dúvida, vital para a formulação de estratégias e para o desenvolvimento de ações mercadológicas efetivas.

Vários são os fatores que envolvem o comportamento de compra organizacional, ou a escolha por um prestador de serviços no mercado industrial, dentre as quais se destacam os fatores ambientais, organizacionais, interpessoais e individuais (KOTLER, 1998). Conforme Robinson et al.,apud Kotler (1998), o processo de compra industrial segue oito estágios, a saber: i) identificação do problema; ii) descrição da necessidade - determinação das características gerais e da quantidade necessária; iii) especificação do produto ou serviço determinação das características técnicas de maior custo-benefício para a aquisição; iv) busca por fornecedores; v) solicitação de propostas; vi) seleção do fornecedor; vii) especificação das condições do pedido; viii) revisão de desempenho - avaliação do fornecedor.

Grönroos (1993) afirma que a percepção do cliente em relação a uma organização está relacionada com a oferta ampliada de serviços por essa empresa. Segundo o autor, o pacote básico de serviços pode ser dividido em três grupos: o serviço essencial, os serviços facilitadores e serviços de suporte. Quando da escolha por um fornecedor, os clientes consideram e avaliam o pacote total, incluindo os serviços facilitadores e de suporte (GRÖNROOS, 1993). A facilidade de acesso ao serviço, a interação do usuário com a organização prestadora do serviço e sua participação no processo de produção são elementos que complementam o pacote básico, formando uma oferta ampliada de serviços que é como um produto total na percepção dos clientes (GRÖNROOS, 1993). Outro fator interveniente no processo de percepção que um cliente tem de uma prestadora de serviços e, portanto, influente no processo de escolha de um fornecedor é a imagem da empresa no mercado.

Segundo o National Council of Physical Distribution, apud Ballou (2001), os elementos do serviço ao cliente podem ser identificados de acordo com o momento em que a 
transação entre o fornecedor e o cliente aconteceu. Esses elementos são agrupados em categorias pré-transação (declaração escrita da política, declaração nas mãos dos clientes, estrutura organizacional, flexibilidade do sistema, serviços técnicos); transação (nível de falta de estocagem, habilidade com pedidos em aberto, elementos de ciclo de pedido, tempo, transbordo); e pós-transação (instalação, garantia, reparo, peças de reposição, rastreamento do produto, reclamações, queixas dos clientes, embalagem, substituição temporária do produto durante reparo).

Já segundo Robinson (2002), o ambiente competitivo atual apresenta um panorama sustentável somente a empresas efetivamente orientadas para o mercado. De acordo com Phillips, apud Robinson (2002), empresas orientadas para o mercado são aquelas que focalizam todas as suas ações mercadológicas em torno de um objetivo integrado, que é o de entregar valor superior ao seu público-alvo, a um custo que permita um lucro aceitável. Conforme Kaplan e Norton (1996) valor, sob a ótica do cliente, contempla três grupos de variáveis: aquelas relacionadas aos atributos do serviço ou produto (tais como funcionalidade, qualidade, preço, tempo de execução); aquelas que definem a imagem da empresa; e aquelas que determinam o relacionamento entre a empresa e seus clientes (como, por exemplo, responsabilidade, suporte e flexibilidade).

Diversos estudos têm demonstrado uma grande influência dos aspectos logísticos na avaliação do nível de serviços das empresas. Entre eles, pode-se citar os estudos de Jackson, Keith e Burdick (1986); Sterling e Lambert (1989); Innis e La Londe (1994); Marr (1994); Heskett (1994), entre outros.

Especificamente, na área de transportes, também já foram desenvolvidos vários estudos sobre os níveis de serviço e os atributos considerados pelos usuários quando da escolha por um fornecedor. Segundo Fleury (2002), os critérios mais utilizados para a avaliação e seleção de um provedor de serviços de transporte, em ordem de importância, são: confiabilidade, preço, flexibilidade operacional e comercial, saúde financeira, qualidade do pessoal operacional e informações de desempenho. Para o autor, a confiabilidade tende a ser o principal critério qualificador, ou seja, a condição mínima para uma empresa ser préqualificada e o preço tende a ser o critério classificador, ou seja, aquele que irá definir qual, entre os fornecedores pré-qualificados, será o transportador escolhido. Ainda, segundo Fleury (2002), a crescente sofisticação das operações de transporte, tanto do ponto de vista tecnológico quanto do ponto de vista de serviços, faz com que a qualidade do pessoal operacional de uma empresa de transporte tenha se tornado um fator importante no processo de seleção de um transportador. 
Em termos de transporte marítimo internacional, alguns autores especificam com maior profundidade o que é, sob ótica dos usuários, nível de serviço e quais são os atributos considerados quando da contratação de um transportador. Devido aos últimos avanços no gerenciamento da cadeia de suprimentos, cada vez mais empresas embarcadoras buscam parceiros com maior sofisticação em seus serviços de transporte (KUMAR, 2003). Com esse propósito, o autor recomenda às empresas que avaliem anualmente seus provedores de transporte marítimo internacional sob os seguintes aspectos: i) desempenho pontual; ii) valor dos fretes; iii) tecnologia de informação; iv) serviço ao cliente; e v) equipamentos e operações.

Segundo Tuna e Silan (2002), conhecer os critérios de escolha de usuários de transporte marítimo internacional é fundamental para a competitividade dos fornecedores desses serviços no mercado atual. Gentry (1996) e Panayides, apud Tuna (2002) afirmam que, devido ao desenvolvimento do marketing de relacionamento como um novo paradigma mercadológico, a natureza do relacionamento entre compradores e transportadores tem sofrido significativas mudanças nos últimos anos. Entende-se marketing de relacionamento como o processo contínuo de identificação e criação de novos valores para os clientes, criando uma parceria que gerará benefícios duradouros para ambas as partes (GORDON, 1998). Seguindo a tendência mundial em todos os setores da economia, o relacionamento entre embarcadores e transportadores tem migrado de uma relação de transação, ou compra-e-venda simplesmente, para uma relação de criação de soluções conjuntas, uma relação estratégica, com vistas a benefícios contínuos de longo prazo (TUNA E SILAN, 2002).

Conforme Tuna e Silan (2002), o processo de escolha por serviços de transporte é dividido em duas etapas: uma em que o exportador escolhe qual o meio de transporte a ser utilizado e outra em que é escolhido quem será o transportador. A decisão sobre a modalidade de transporte é complexa e envolve uma série de fatores, tais como características do produto (peso, volume, valor comercial), urgência de entrega, ponto de destino e opções de modais no mercado. A decisão sobre o transportador, apesar de parecer mais simples, também apresenta uma considerável complexidade.

Segundo Brooks (1995), o custo do serviço e a capacidade de resolver problemas são os atributos mais valorizados pelos clientes no processo de escolha de um armador. Já Kent e Parker (1999) destacam que confiabilidade, disponibilidade de equipamentos e freqüência de navios são os principais atributos considerados pelos clientes quando da escolha de um transportador.

Tuna e Silan (2002) realizaram um estudo sobre os critérios de seleção de 
ISSN 1676 - 1901 / Vol. 5/ Num. 2/ Junho de 2005

transportadores de linha regular no Porto turco de Izmir. Por me io de uma pesquisa aberta direcionada a 200 gerentes de empresas usuárias de transporte marítimo, no referido porto, foi elaborada uma lista de 24 atributos considerados por esses gerentes quando da seleção de um transportador. Tal lista foi apresentada aos mesmos usuários em um segundo momento para que, utilizando-se de uma escala de 1 a 5, pudessem informar qual o grau de importância de cada atributo. O questionário foi respondido por 37 empresas, representando um retorno de 18,5\%. Entre os 24 atributos pesquisados, os dez aspectos mais importantes foram: i) entregar a carga sem danos; ii) emitir documentação de embarque corretamente; iii) entregar a carga no prazo acordado; iv) possuir agilidade em lidar com problemas; v) informar mudança de programação de navios; vi) enviar cotações de fretes de forma precisa; vii) responder com rapidez a reclamações; viii) emitir documentação de embarque rapidamente; ix) enviar prontamente remessas urgentes; e x) informar clara e corretamente o cliente sobre custos, com escores variando entre 4,84 e 4,43. Baseados nos dados dessa pesquisa, Tuna e Silan (2002) elaboraram também uma lista de sete fatores que representam os critérios de escolha de um transportador marítimo de linha regular, determinando os atributos de cada fator e concluíram que o fator mais importante é aquele relacionado com a confiabilidade e competência do transportador.

No que se refere ao nível de serviço e aos critérios de escolha portuária, também foram identificados na bibliografia alguns estudos, destacando-se as publicações de Murphy et al. (1992), Murphy e Daley (1994); Novaes e Vieira (1996); Monteiro et al. (2001); Tongzon (2002), entre outras.

O que se observa nos trabalhos publicados sobre níveis de serviços na área de transporte e logística é que os mesmos apresentam um aspecto comum: na maioria dos casos, o preço não é o fator preponderante de escolha de um fornecedor. Tal prerrogativa parece verdadeira, uma vez que vivemos na era do "valor", em que "custo"_é somente uma das variáveis consideradas.

Apesar da extensa bibliografia sobre serviço ao cliente, atributos do nível de serviço logístico, critérios de escolha de um prestador de serviços, de transportadores e de portos, não foram encontrados trabalhos específicos sobre avaliação do nível de serviço de NVOCCs e dos critérios de escolha desse tipo de empresa, o que ressalta a importância do presente estudo.

\section{METODOLOGIA}


A população-alvo da pesquisa correspondeu aos usuários dos serviços de consolidação marítima da empresa estudada localizados no estado do Rio Grande do Sul, distribuídos entre agentes de cargas e exportadores. Foram consideradas 158 empresas registradas como clientes no período de janeiro a dezembro de 2002. Os respondentes em cada empresa foram as pessoas responsáveis pela contratação dos serviços de transporte.

Inicialmente, tendo como base a revisão da bibliografia e uma pesquisa de satisfação já aplicada pela empresa em anos anteriores, foi elaborada uma listagem inicial dos atributos a serem considerados no estudo. A seguir, essa listagem foi submetida por telefone a um número indeterminado de profissionais de empresas com experiência na utilização de serviços de consolidação marítima no estado do Rio Grande do Sul, escolhidos por conveniência, até que os três últimos não agregassem nenhum novo atributo à lista.

Dessa forma, obteve-se a seguinte relação de atributos a serem considerados na pesquisa: frete; tempo de trânsito; regularidade; frequiência; abrangência/cobertura dos serviços; qualidade e agilidade na impressão de documentação de embarque; serviço de informação; atendimento e cordialidade dos colaboradores; preparo técnico da equipe de colaboradores e imagem no mercado/reputação. Além desses dez atributos, foi considerada também a satisfação geral em relação aos serviços da empresa.

O grau de satisfação dos clientes foi escalonado numericamente de 1 a 7 , sendo o extremo inferior identificado como "extremamente insatisfeito" e o extremo superior como "extremamente satisfeito".

Os questionários foram enviados por e-mail, durante três semanas, no período de 13 a 31 de outubro de 2003. Ao final do período, foram obtidas 37 respostas, correspondendo a 23,42\% do total de questionários enviados. Cabe salientar, também, que essas 37 respostas foram obtidas de empresas que, juntas, representaram 94,25\% do total de cargas embarcadas pela organização no ano de 2002.

Os graus de satisfação foram atribuídos pelos próprios respondentes e a importância de cada atributo foi obtida de forma indireta, por meio de regressão linear múltipla. Nas análises de regressão múltipla e de correlação foi utilizado o programa StatGraphics Plus, versão 2.1, tendo sido considerados níveis de confiança de $95 \%$ e $99 \%(\alpha=0,05$ e $\alpha=0,01)$. Após a tabulação dos dados, foi analisado o nível de serviço da empresa estudada, tendo como parâmetros os níveis de satisfação em cada atributo e a relação da satisfação em cada atributo com a satisfação geral atribuída pelos respondentes. 


\section{RESULTADOS}

As respostas quanto aos níveis de satisfação indicaram uma satisfação geral média de 6,162 e um desvio-padrão de 0,727. Pode-se considerar essa satisfação geral elevada, já que a escala utilizada na pesquisa variava entre 1 (extremamente insatisfeito) e 7 (extremamente satisfeito). Os atributos em que se observaram os maiores níveis de satisfação foram o atendimento e cordialidade dos colaboradores e a imagem da empresa no mercado, ambos com satisfação média superior a 6,5. Por outro lado, o frete e o tempo de trânsito foram os atributos pior avaliados pelos respondentes, apresentando valores médios de satisfação de 5,865 e 5,649, respectivamente. Ainda assim, os níveis de satisfação obtidos foram altos, considerando-se a escala utilizada. Os demais atributos ficaram em uma posição intermediária, com satisfação média variando entre 6,270 e 6,027.

Tabela 1: Níveis de satisfação atribuídos pelos respondentes

\begin{tabular}{lcc}
\hline Atributo & $\begin{array}{c}\text { Satisfação } \\
\text { Média }\end{array}$ & $\begin{array}{c}\text { Desvio } \\
\text { Padrão }\end{array}$ \\
\hline 1. Frete & $5,865(9)$ & 1,1096 \\
2. Tempo de trânsito & $5,649(10)$ & 1,0857 \\
3. Regularidade & $6,135(7)$ & 1,1586 \\
4. Freqüência & $6,027(8)$ & 1,2130 \\
5. Abrangência e cobertura dos serviços & $6,189(5)$ & 0,9076 \\
6. Qualidade e agilidade na documentação & $6,270(3)$ & 0,6519 \\
7. Serviço de informação & $6,162(6)$ & 0,9578 \\
8. Atendimento e cordialidade & $6,595(1)$ & 0,6855 \\
9. Preparo técnico da equipe & $6,243(4)$ & 0,7960 \\
10. Imagem no mercado/reputação & $6,514(2)$ & 0,6507 \\
SATISFAÇÃo GERAL & $\mathbf{6 , 1 6 2}$ & $\mathbf{0 , 7 2 7}$ \\
\hline
\end{tabular}

A relação entre a satisfação em cada atributo e a satisfação geral atribuída pelos respondentes foi medida por meio de regressão linear múltipla, tendo sido considerada a satisfação geral como variável dependente e os diferentes atributos como variáveis independentes. Para a análise de regressão múltipla e de correlação foi utilizado o programa StatGraphics Plus, versão 2.1. 
Tabela 2: Resultados da regressão múltipla

\begin{tabular}{c|ccc} 
Modelo & $\mathbf{R}^{\mathbf{2}}$ & $\mathbf{R}^{\mathbf{2}}$ Ajustado & $\begin{array}{c}\text { Erro padrão de } \\
\text { estimação }\end{array}$ \\
\hline $\mathbf{1}$ & $79,20 \%$ & $78,61 \%$ & 0,3363 \\
$\mathbf{2}$ & $86,46 \%$ & $85,66 \%$ & 0,2753 \\
$\mathbf{3}$ & $92,90 \%$ & $92,25 \%$ & 0,2024 \\
$\mathbf{4}$ & $94,41 \%$ & $93,71 \%$ & 0,1823 \\
\hline
\end{tabular}

1) Atributos: PREPTEC

2) Atributos: PREPTEC, BL

3) Atributos: PREPTEC, BL, FREQ

4) Atributos: PREPTEC, BL, FREQ, REG

Com um valor de $\alpha=0,05$, somente as variáveis preparo técnico da equipe (PREPTEC), agilidade e qualidade na emissão da documentação de embarque (BL), freqüência (FREQ) e regularidade (REG) apresentaram significância estatística. Cabe salientar que essas variáveis também foram significativas a um nível de confiança de $99 \%$ ( $\alpha$ $=0,01)$.

As demais variáveis (tempo de trânsito, atendimento e cordialidade da equipe, cobertura e abrangência dos serviços, imagem e serviço de informação) não foram consideradas significantes a um nível de confiança de $95 \%$.

A equação que descreve o modelo é a seguinte:

$$
\mathrm{SG}=-0,11-0,21607 * \mathrm{REG}+0,426471 * \mathrm{FREQ}+0,47705 * \mathrm{BL}+0,326307 * \text { PREPTEC }(1)
$$

onde SG: Satisfação Geral

REG: Regularidade

FREQ: Freqüência

BL: Agilidade e qualidade na emissão da documentação de embarque

PREPTEC: Preparo técnico da equipe

O modelo explica que a satisfação geral dos respondentes (variável dependente) é bastante influenciada pelos atributos agilidade e qualidade na emissão da documentação de embarque (BL), freqüência (FREQ), regularidade (REG) e preparo técnico da equipe 
(PREPTEC). Utilizando-se tais atributos na análise, obteve-se um coeficiente $\mathrm{R}^{2}$ de $94,41 \%$, o que indica uma relação relativamente forte entre essas variáveis e a satisfação geral. Em outras palavras, pode-se perceber que a criação de valor para os clientes da organização depende muito de seu desempenho nesses fatores.

Pode-se perceber que os atributos qualidade e agilidade na impressão dos documentos, preparo técnico da equipe, freqüência e regularidade apresentam grande peso na satisfação geral, sendo aspectos relevantes para a manutenção dos clientes da empresa. Os demais atributos, embora também possam ser importantes para a proposição de valor da organização, não apresentaram relação significativa com a satisfação geral. É importante destacar que a empresa obteve níveis de satisfação elevados não só nesses atributos mais relacionados com a satisfação geral, mas também nos demais, conforme se pode observar na tabela 1.

\section{CONCLUSÕES}

Os resultados obtidos na pesquisa permitem conclusões significativas. A metodologia utilizada confirma as expectativas da organização, que busca a diferenciação de seus serviços principalmente por meio do relacionamento com o cliente e do serviço de informação qualificado. Tais prerrogativas parecem bastante relacionadas com os atributos em que se verificaram os maiores níveis de satisfação, como é o caso do atendimento e cordialidade, da imagem no mercado/reputação, da qualidade e agilidade na impressão da documentação e do preparo técnico da equipe. A cordialidade no atendimento e a imagem da empresa no mercado, embora não tenham apresentado significância estatística, foram os atributos em que se verificaram os maiores níveis de satisfação.

O serviço de informação, qualificado pelos clientes como satisfatório, pode ser entendido como um diferencial da organização perante a concorrência, por se tratar de um componente que contribui para a manutenção de um atendimento diferenciado e próximo ao cliente, além de gerar pontos positivos à imagem da empresa no mercado. Por essa razão, sugere-se à empresa que mantenha e aprimore seu sistema de informação, ainda que não se tenha verificado significância estatística nesse atributo.

Pesquisas anteriores da organização já apresentavam a agilidade e a qualidade de impressão da documentação de embarque como fator importante na decisão de compra do cliente. Por serem os documentos de embarque fundamentais para o recebimento do valor da exportação, esses se tornam pontos sensíveis para os clientes da empresa, devendo ser constantemente monitorados. 
A freqüência e a regularidade, atributos significativos em que foram observados níveis de satisfação ligeiramente inferiores, deverão ser revistas pela organização, visando a uma melhoria de seu nível de serviço. Em relação à freqüência de suas saídas, a empresa deverá rever suas parcerias com os armadores, buscando identificar fornecedores com saídas mais freqüentes e adequadas à demanda. Já em relação à regularidade dos serviços, deverá implementar um índice de mensuração com vistas a monitorar seu desempenho nesse quesito. Sugere-se, ainda, que a empresa reveja seus procedimentos operacionais, visando a identificar possíveis focos de problemas m realização dos embarques previstos e, dessa forma, busque melhorar seu desempenho nesse atributo.

O frete e o tempo de trânsito apresentaram-se estatisticamente irrelevantes e com os menores níveis de satisfação, provavelmente devido à similaridade de condições verificadas entre a organização estudada e o mercado, o que acaba por não conferir-lhe nenhuma singularidade. Entretanto, a empresa também deverá monitorar esses fatores, pois na existência de uma diferença significativa entre os valores aplicados e a média de mercado, esses atributos tendem a ganhar importância para os usuários, podendo representar a perda de determinados mercados para novos entrantes ou concorrentes já estabelecidos.

O estudo apresentou contribuição à organização por confirmar algumas de suas crenças e valores no que se refere às necessidades e percepções de seus clientes. Diante análise de cada atributo, pode-se concluir que, embora sejam preparo técnico; qualidade e agilidade na impressão da documentação; regularidade e freqüência os fatores que apresentaram maior relação com a satisfação geral, os demais atributos também apresentam importância, devendo ser acompanhados pela empresa de forma constante e regular.

Observou-se que a organização apresenta elevados níveis de satisfação de seus clientes em fatores considerados relevantes, o que lhe confere uma posição favorável à retenção das empresas respondentes. Embora a pesquisa tenha sido direcionada a clientes de uma única empresa, devido à grande participação da mesma em seu mercado de atuação (quase 50\%) e da grande representatividade dos respondentes no total de cargas embarcadas pela organização $(94,25 \%)$, as conclusões podem ser importantes para o setor como um todo. Os resultados indicam uma predominância dos fatores qualitativos (como preparo técnico da equipe, qualidade e agilidade na emissão dos documentos) e daqueles relacionados com tempo (regularidade e freqüência) sobre o frete na escolha de um consolidador de cargas marítimas. Entretanto, sugere-se que sejam realizados movos estudos em outras regiões e com outras amostras, considerando um maior número de usuários, com o objetivo de corroborar tais resultados. Também podem ser feitas algumas alterações na listagem de atributos, visando 
a evitar ou reduzir a colinearidade, a exemplo do que foi observado nos atributos regularidade

e frequência e, em menor grau, nas variáveis serviço de informação e atendimento e cordialidade dos colaboradores.

\section{REFERÊNCIAS}

AGÓS, Francisco Enríquez. El Plan Estratégico: un instrumento para la gestión portuaria. Valência: IPEC, 1993.

BALLOU, Ronald H., Gerenciamento da cadeia de suprimentos: planejamento, organização e logística empresarial. 4 ed. Porto Alegre: Bookman, 2001.

BOWERSOX, Donald J.; CLOSS, David J., Logística empresarial: o processo de integração da cadeia de suprimentos; São Paulo: Atlas, 2001.

BRODIE, Peter R. Dictionary of shipping terms . London: LPP, 1985.

BROOKS M. R. , Understanding the Ocean Container Market - A Seven Country Study, Maritime Policy and Management, Vol.22, No.1, pp.39-49, 1995.

CENTRONAVE - Centro de Navegação do Porto de Santos, Estatística mensal de exportação do Brasil, agosto de 2003.

CHRISTOPHER, Martins. O Marketing da Logística. São Paulo: Futura, 1999.

NOVAES, Antônio Galvão Naclério. Economia e tecnologia do transporte marítimo. Rio de Janeiro: Almeida Neves Editores, 1976.

RUST, Roland T.; ZEITHAML, Valarie A.; LEMON, Katherine N. O valor do cliente. Porto Alegre: Bookman, 2001.

FARIA, Sergio Fraga Santos, Fragmentos da história dos transportes. São Paulo: Aduaneiras, 2001.

FLEURY, Paulo Fernando, Gestão Estratégica do Transporte; COPPEAD-Universidade Federal do Rio de Janeiro, v.1, 2002, disponível em <http://www.cel.coppead.ufrj.br/frestrat-trans.htm, acesso em 28 de agosto de 2003. 
GENTRY, J.J., The Role of Carriers in Buyer-Supplier Strategic Partnerships: A Supply Chain Management Approach, Journal of Business Logistics, Vol.17 No.2, pp.35-56, 1996

GORDON, Ian, Marketing de Relacionamento, 3 ed. São Paulo: Futura, 1998.

GRÖNROOS, Christian, Marketing: gerenciamento e serviços: a competição por serviços na hora da verdade. Rio de Janeiro: Campus, 1993.

HESKETT, James L. Controlling Customer Logistics Service. International Journal of Physical Distribution and Logistics Management 24, nº 4, 1994.

INNIS, Daniel I; LALONDE Bernard J. Customer Service: The Key to Customer Satisfaction, Customer Loyalty and Market Share. Journal of Business Logistics $15, \mathrm{n}^{\mathrm{o}} 1$, 1994, p. 1-27.

JACKSON, Donald W.; KEITH, Janet E.; BURDICK, Richard K. Examining the Rela tive Importance of Physical Distribution Service Elements. Journal of Business Logistics 7, $\mathrm{n}^{\mathbf{o}} 2$ (1986), p. 14-32.

KAPLAN, R.S. and NORTON, D.P., The Balanced Scorecard, Harvard Business School Press, Boston, p. 74-76, 1996

KEEDI, Samir, Contêiner e Globalização, disponível em <http://www.guialog.com.br $>$, acesso em 12 de outubro de 2002.

KENT, J.L. and PARKER, R.S., International Containership Carrier Selection:

Shippers/Carriers Differences, International Journal of Physical Distribution \& Logistics Management, Vol.29, No.6, pp.398-408, 1999

KOTLER, Philip, Administração de marketing: análise, planejamento, implementação e controle. 5.ed. São Paulo: Atlas, 1998.

KUMAR, Shashi; A decision support model for the liner shipping competition policy debate; Loeb-Sullivan School- Maine Maritime Academy: Maine 2003.

MARR, Norman E. Do Managers Really Know What Service Their Customers Require? International Journal of Physical Distribution and Logistics Management 24, $\mathrm{n}^{\mathbf{0}}$ 4, 1994, p. 24-31.

MONTEIRO, Ana Beatriz Figueiredo de Castro; MARTINS, Wagner Colombini; Rodrigues, Fernando Howat. O processo de decisão do modal no transporte de carga. In: Gestão 
Logística do Transporte de Cargas. Caixeta-Filho, José Vicente e Martins, Ricardo Silveira (orgs.). São Paulo: Atlas, 2001.

MURPHY, Paul R.; DALEY, James M. A Comparative Analysis of Port Selection Factors. Transportation Journal; Volume 34, nº 1, Fall 1994, p.15-21.

MURPHY, Paul R.; DALEY, James M. ; DALEMBERG, Douglas R. Port Selection Criteria: An Application of a Transportation Research Framework. Logistics and Transportation Review, Volume 28, nº 3, Sep 1992, p.237-255.

NOVAES, Antônio Galvão Naclério. Economia e tecnologia do transporte marítimo. Rio de Janeiro: Almeida Neves Editores, 1976.

NOVAES, Antonio Galvão; VIEIRA, Hélio Flávio; O nível de serviço logístico portuário sob a ótica dos exportadores; Revista Gestão e Produção; v.3, n.3, 1996 p.290-306.

OECD - Organisation for Economic Co-operation and Development. Directorate for Science, Technology and Industry. Division of Transport. Competition Policy in Liner Shipping. April, 2002.

PORTER, Michael. A estratégia Competitiva. 7. ed, Rio de Janeiro:Campus, 1986.

ROBINSON, Ross; Integrated and intermodal freight systems: a conceptual framework; Melbounre: International Transport, 2002.

RUST, Roland T.; ZEITHAML, Valarie A.; LEMON, Katherine N. O valor do cliente. Porto Alegre: Bookman, 2001.

STERLING, Jay U.; LAMBERT, Douglas M. Customer Service Research: Past, Present and Future. International Journal of Physical Distribution and Logistics Management $19, \mathrm{n}^{\mathbf{o}}$ 2, 1989, p. 17.

TONGZON, Jose. Port Choice in a Competitive Environment. IAME - International Association of Maritime Economists Panama 2002 Conference Proceedings, disponível em http://www.eclac.cl/Transporte/perfil/iame_papers.asp, acesso em 10 de setembro de 2003.

TRAINMAR - Trainning in Maritime, disponível em <http://.www.trainmar.com.br>, acesso em 11 de agosto de 2003.

TUNA, Okan e SILAN, Mustafa. Freight transportation selection criteria, IAME International Association of Maritime Economists. Panama 2002. Conference Proceedings, 
disponível em http://www.eclac.cl/Transporte/perfil/iame_papers.asp, acesso em $10 \mathrm{de}$ setembro de 2003.

UNRUH, James A. Bons clientes - Ótimos Negócios . Rio de Janeiro: Campus, 1998.

Artigo recebido em 06/01/05 e aceito para publicação em 15/06/05 